\title{
FIT PROCESSIO ET CANTANTUR ANTIPHONAE SEQUENTES. TIPOLOGÍA DE LAS FORMAS DE MÚSICA LITÚRGICA EN LOS LIBROS PROCESIONALES
}

\author{
David Andrés Fernández \\ Universidad Austral de Chile \\ dandres@uach.cl
}

\section{Resumen}

El repertorio musical de las procesiones de la liturgia latina constituye una materia especial dentro de los estudios del denominado canto llano en occidente. A pesar de que cada una de las diversas formas litúrgico-musicales que pueden encontrarse en este repertorio procesional (antífonas, responsorios, letanías, himnos, etc.) han sido suficientemente estudiadas, las investigaciones en esta temática suelen hacer referencia a su definición y uso dentro de un contexto litúrgico determinado; el de la Misa o el del Oficio Divino. Por esta razón, este texto tiene como objetivo sintetizar los aspectos descriptivos y funcionales de dichas formas de música litúrgica en su uso procesional, dentro de un marco de investigación de un corpus que sea extrapolable al conjunto de los libros procesionales del Medio Aevo.

\section{Palabras clave}

Liturgia, música, procesión, Edad Media, clasificación.

\begin{abstract}
The musical repertoire of processions of the Latin liturgy has had a singular treatment in the Western plainchant scenario. Scholars have focused their studies on liturgical music genres (antiphons, responsories, letanies, hymns,...) on issues related with their definitions and usages, based on a certain liturgical context; i.e., Mass or Divine Office. For this reason, this paper aims to summarize the relevant descriptive and functional aspects of these forms of liturgical music in its processional praxis, in the context of a research of a corpus, which could be inferred to the medieval processional books.
\end{abstract}

Keywords: liturgy, music, procession, Middle Ages, classification. 


\section{INTRODUCCIÓN}

El repertorio de piezas musicales de canto llano de la tradición franco-romana, más comúnmente conocido como Canto Gregoriano, suele dividirse habitualmente en dos tipos de repertorios, el de la Misa y el del Oficio. Sin embargo, existen ciertas piezas litúrgico-musicales específicas que ha permitido a los especialistas identificar un tercer tipo de repertorio: el de las procesiones.

La música destinada a las procesiones litúrgicas o, en otras palabras, la música litúrgica procesional puede encontrarse, a lo largo de la Edad Media, escrita en diferentes libros. Las escasas referencias bibliográficas sobre la historia del libro procesional, nos muestran usualmente el desarrollo de este tipo librario hasta finales de la Edad Media. Es más, las fuentes primarias atestiguan que las piezas litúrgico-musicales utilizadas en las procesiones fueron copiadas inicialmente en los libros graduales a partir del siglo Ix, posteriormente en libros compuestos, tales como prosarios, troparios y antifonarios (desde el s. $\mathrm{x}$ ), y finalmente, al ampliarse el repertorio, en libros independientes denominados procesionales - estrictamente hablando- - desde el siglo XII en adelante (Gy, I990: 9I-I26; Palazzo, 1998: 229-232).

Por otra parte, el contenido de un libro procesional puede variar sustancialmente tanto en la cantidad como en la variedad de piezas litúrgico-musicales que alberga, debido principalmente a varios factores, como la época en que fue confeccionado, institución a la que fue destinada o su tipología. ${ }^{\mathrm{I}}$ Es decir, en un libro procesional, podemos encontrar unas u otras formas litúrgico-musicales dependiendo del momento de la historia en el que el libro fue compuesto o copiado (y de su origen, entre otros factores).

No obstante, en principio y de forma general, un procesional puede contener cualquier tipo de canto. En palabras de Roederer (I97I: III):

"The processional repertory is very large and unusually diverse in musical style. It includes chant which range from the reciting tone invocations of the rogation days to elaborate antiphons for major feasts, antiphons which rival in size and complexity the office responsories."

Es más, en nuestras indagaciones sobre el procesional medieval aragonés (Andrés Fernández, 20I2), el cual nos sirve aquí como guía de trabajo para realizar nuestra propuesta de clasificación para este repertorio, hemos observado que un

${ }^{1}$ Para una clasificación sobre los tipos de procesionales, véase Huglo (1999, 2004: I, 43*-55*). 
procesional puede incluir letanías ${ }^{2}$ y antífonas litánicas (que ya encontramos en los graduales o antifonarios de la misa del siglo Ix), antífonas procesionales procedentes también de otros libros litúrgicos (como hemos visto; antifonarios del oficio y prosarios-troparios principalmente), responsorios adaptados a las festividades pertinentes (extraídos de los breviarios y antifonarios), así como otras composiciones como los versus e himnos procesionales. Asimismo, el procesional es una tipología libraria a la que se le puede haber ańadido, por ejemplo a través de la inclusión de un cuadernillo, cualquier otro tipo de repertorio litúrgico, ya sea con función procesional o no. Sirva como ejemplo el procesional de La Seo de Zaragoza datado entre los siglos XIV y XV, cuyo último cuadernillo incluye oraciones e himnos de uso no procesional. ${ }^{3}$

Por otra parte, la utilización y uso de todos estos tipos de piezas procesionales puede ser diversa y, por tanto, pueden aparecer en diferentes momentos de la liturgia, si bien su misión principal es la de acompañar musicalmente, valga la redundancia, las procesiones litúrgicas antes de la misa (salida desde el coro, servicio en la estación o el regreso a la iglesia), ${ }^{4}$ antes del oficio de matines y vísperas, y en procesiones especiales; un acto que puede tener lugar en diversos momentos. ${ }^{5}$

De cualquier modo, a pesar de las clasificaciones disponibles, aquí proponemos una división de las formas de música litúrgica procesional basándonos en su origen. Por tanto, distinguiremos, en primer lugar, aquellas piezas que pertenezcan al fondo procesional propio, entendiendo éste como el estrato de repertorio procesional más antiguo y, en segundo lugar aquellas de lo que denominaremos el fondo procesional prestado, es decir, los cantos que fueron tomados prestados de otros repertorios (del Oficio Divino normalmente) para ser utilizados en las procesiones. De este modo, presentamos a continuación las posibles formas litúrgico-musicales utilizadas en las procesiones basándonos en esta clasificación. En cada caso, hemos realizado una breve descripción, explicando además su etimología, función, estructura e interpretación, siempre orientados estos últimos aspectos a su destino procesional. ${ }^{6}$

2 Las letanías son consideradas una forma musical, puesto que es un género mixto que comparte prosodia, recitado y ciertos elementos musicales (Huglo, "Processional").

3 Zaragoza, Biblioteca Capitular de Zaragoza, ms. 4I-II7, ff $.96-89$ (E-Zs 4I-II7).

${ }^{4}$ No confundir ésta con la antífona de introito del propio de la misa (antiphona ad introitu).

5 Para una aproximación sobre las diversas formas de procesiones litúrgicas, véase Bailey (I968) y espacialmente Martimort (1955).

${ }^{6}$ Tenga en cuenta el lector que sólo se estudiarán aquellas formas que aparecen en los procesionales medievales aragoneses: antífonas, letanía de los santos, preces, versus, responsorios e himnos. 
FORMAS DEL DENOMINADO FONDO PROCESIONAL PROPIO

\section{Antifona}

Etimológicamente "antífona" (del griego $\alpha v \tau i ́ \varphi \omega v o \zeta$, del latín antiphöna) significa voz opuesta o voz contra voz. El término es complejo de definir. ${ }^{7}$

Desde la antigua Grecia, hay testimonios que atestiguan el uso del término, que era empleado, en este caso, para definir un intervalo de octava, distinguiéndolo del intervalo de unísono. Asimismo, a lo largo de la historia, aparece en diversas culturas y momentos para representar diversos conceptos, aunque todos ellos relacionados entre sí, denotando ora alternancia en el canto o en las voces que participan en el mismo, ora una "forma musical o un estilo de ejecución" (Claire, 1980: 27-46).

Por tanto, hay que ser prudentes a la hora de definir el término (Nowacki, I990: 79-9I):

"In the light of our current knowledge, it seems prudent not to define 'antiphon' too narrowly. It may have involved various types of participatory singing, and various types of alternation, and was probably asociated $[s i c]$ at first with the sites at which such singing was heard and the spirit of contentiousness that underlay it".

Vista la cita del párrafo anterior, uno puede entender por qué los diversos autores han tomado diversas clasificaciones y difieren en su perspectiva al analizar la forma musical "antífona".

M. Righetti las clasifica en cuatro grandes categorías: salmódicas, evangélicas, históricas e independientes. Su destino puede ser el Oficio Divino, ${ }^{8}$ antífonas de Benedictus y de Magnificat, ${ }^{9}$ antífonas del propio de la misa (de introito, ofertorio y comunión), marianas, versificadas y procesionales. Para el autor, la funcionalidad de la antífona es doble: musical y litúrgica; musical porque designa y prepara el tono en el que deberá ser cantado el salmo, y litúrgica porque la antífona su-

Para consultar acerca del corpus documental, y a la espera de un publicación en prensa acerca de este corpus, véase Andrés Fernández (2013: 5 ).

7 Para una descripción etimológica completa y una perspectiva histórica del concepto, véase (Huglo \& Halmo, "Antiphon"; Saulnier, 2005: 25-39).

${ }_{8}^{8}$ Procedentes normalmente de breviarios y salterios, con texto breve, acompañan al recitado de los salmos en los oficios (laudes, tercia, sexta, etc.).

9 Tomadas del Nuevo Testamento: respectivamente Lc.I, 68-79, alusivo a Zacarías, cantadas en Laudes; y Lc. I, 46-55, alusivas a la Virgen María, entonadas en el oficio de Vísperas. 
giere el pensamiento dominante a través del cual la Iglesia invita a interpretar el salmo (Righetti, I955: II94-I199).

Para M. Huglo, sin embargo, las antífonas se dividen en dos tipos. Por un lado, aquéllas destinadas a los salmos para los oficios de maitines, laudes y vísperas, y, por otro lado, el resto, incluyendo aquí como subtipos las antífonas del salterio, las antífonas con versos, las antífonas de Benedictus y de Magnificat, las antífonas destinadas a la misa (introito y comunión), las antífonas marianas, las antífonas procesionales y las antífonas versificadas. La mayor parte de ellas tienen texto bíblico y la composición de sus melodías es diversa (Huglo \& Halmo, "Antiphon").

D. Saulnier, por su parte, establece siete tipos, invitándonos a considerar la antífona como (Saulnier, 2005: 40):

"une réalité liturgico-musicale complexe, qui recouvre en fait des formes musicales et des mises en œuvre pratiques distinctes".

Estos tipos serían: uno) alternancia o "antiphonie", dos) la respuesta a la salmodia responsorial por versos, tres) el estribillo ${ }^{\mathrm{IO}}$ de la salmodia responsorial por estrofas, cuatro) la antífona como comienzo y/o conclusión del salmo, cinco) la antífona "de aparato", " ${ }^{\text {II }}$ seis) la antífona de procesión, y, siete) la antífona "de devoción” (Saulnier, 20IOa, 20Iob).

\section{La antifona procesional}

Las antífonas procesionales del denominado fondo procesional propio podrían ser definidas como aquellas antífonas de mayor antigüedad con función pura y estrictamente procesional (acompañan musicalmente el acto de procesión), las cuales aparecen escritas en los graduales y antifonarios más antiguos de Occidente (recopilados en AMS y CAO). ${ }^{12}$ Es decir, son aquellas antífonas cuyas rúbricas están directamente vinculadas a la Letanía Mayor, Letanías Menores o Rogativas

Io Nota del Traductor (NT en adelante): Del original "Refrain", traducido aquí como estribillo, es decir, como la parte que se repite.

II NT: Del original "L'antienne 'd'apparat' ".

${ }^{12}$ AMS = Hesbert (1935); CAO = Hesbert (1963-I979). 
y las procesiones rituales de la Candelaria (Purificación), la Adoración de la Cruz (Viernes Santo) y el Miércoles de Ceniza (Huglo, I988: IIO-III)..$^{13}$

Otra definición de la antífona procesional podría ser la que sigue (Hiley, I993: IOO):

"Processional antiphons are generally ornate chants, some very long indeed, with lengthy melismas. Some have an equally ornate verse and were performed responsorially, that is, with a repeat of all or part of the first section, the respond after the verse. Others appear with an incipit for the chanting of a psalm, but it is not clear how many verses would have been sung (presumably in alternation with the antiphon)."

Como se observa en esta cita, parece que existen diversos tipos de antífonas procesionales. Por ello, a pesar de que existen algunas clasificaciones de las antífonas procesionales — también llamadas per viam—, estableceremos aquí una división de las mismas basadas en el modo de aparición en los procesionales aragoneses, estableciendo tres categorías que concordarán con las encontradas en las fuentes de toda la Edad Media.

I) La primera de ellas sería la antífona con salmo, que respetaría una forma de interpretación musical tripartirta:

Antífona - Salmo - Antífona

a./ - ps./ - a./

Para este caso, la antífona se presenta seguida de un salmo (versículo del salmo) o una diferencia salmódica. Suele venir escrita de forma binaria: Antífona - Salmo. En la mayor parte de las ocasiones, el salmo viene vagamente indicado; normalmente se advierte simplemente por el íncipit o por la diferencia salmódi$c a{ }^{\mathrm{I}}{ }^{4}$ Es, en este último caso, deber de los cantores saber qué salmo han de cantar después de la antífona.

${ }^{13}$ Más tarde recogidas en las tablas I, II y parte de la III del catálogo de procesionales de Huglo (1999, 2004: I, 43*-47*).

${ }^{14}$ Esto es, la terminación musical con la que acaba cada uno de los versículos de un salmo cuyo homólogo textual es indicado ora por su íncipit (e.g.: Miserere mei, para el salmo 50), ora por el final de la doxología (Seculorum amen), que normalmente se representa por su vocalización euouae o sus diferentes variantes: Gloria Patri et Filii et ... et in secula seculorum, amen. 
Estas antífonas procesionales (con salmo) son cantadas al comienzo de la estación o antes de llegar a ella y suelen ser tomadas del oficio o incluso del introito de la misa. Para este último caso, sí suelen encontrarse asociadas al canto de un salmo determinado e indicado en el manuscrito (Colette, 1976: 47).

2) El segundo tipo de antífona procesional, mayoritario en número para este repertorio, es la antífona independiente que prescinde de salmo. Estas antífonas tienen un texto generalmente muy desarrollado y su música suele ser bastante ornada, incluyendo melismas (Hiley, I993: I00). Colette advierte que estas antífonas tienen una gran complejidad modal, siendo incluso bastante difícil clasificarlas dentro de los ocho modos de los criterios habituales (Colette, 1976: 47).

Las antífonas autónomas se interpretan como cantos per se. Además, los procesionales suelen contener un gran numero de ellas, siendo, de hecho, el corpus principal de la mayoría de estos libros.

3) El tercer tipo es la antífona procesional versificada. Ésta puede aparecer tal cual en los manuscritos, es decir, con versos, o puede ser una antífona independiente (del tipo anterior) que ha sido convertida en antífona versificada al añadir la indicación $v$. / vs. (versiculus) en un punto concreto de la misma. En este último caso, las adiciones pueden funcionar como marca o punto de inicio de una estación dentro de una procesión.

Mostramos, coincidiendo con la triple clasificación descrita, tres ejemplos, uno para cada tipo de antífona, aplicadas al fondo propio procesional:

Antífona con salmo: ${ }^{15}$

a./ Exsurge Domine adjuva nos

ps./ Deus auribus

Antífona independiente: ${ }^{16}$

a./ Immutemur habitu in cinere

is Para la Letanía Mayor (AMS 20I).

${ }^{16}$ Para el Miércoles de Ceniza (AMS 37). 
Antífona versificada: ${ }^{17}$

a./ Collegerunt pontifices

v./ Unus autem

\section{Letanias}

Al igual que el anterior caso, el término "letanía" (del griego $\lambda \imath \tau \eta$ = súplica; del latín letania) puede definir o referirse a varios conceptos.

Primeramente, habría que distinguir entre la letanía como celebración litúrgica de la letanía como forma litúrgico-musical. En otras palabras, la Letanía Mayor y Letanías Menores o Rogativas son celebraciones litúrgicas, las cuales contienen, además de ciertos elementos musicales, la letanía como forma litúrgico-musical. Es más, esta forma constituye normalmente el elemento central de aquéllas celebraciones.

Las letanías, como celebraciones litúrgicas, con sus elementos musicales, pueden encontrarse en tres momentos: ${ }^{18}$

- Letanía Mayor, instituidas en Roma a mediados del siglo vi, se celebran el 25 de abril y tienen un carácter más bien festivo si se compara con el resto de letanías ya que acontecen en pleno tiempo pascual (Guilmard, 2009: I0).

- Letanías Menores o Rogativas, con pleno carácter penitencial, provienen de Francia, siglo v, y se celebran tres días antes de la Ascensión. Esta celebración, en sus inicios, también tuvo lugar en Milán y en España. Más tarde, c. 8oI, fueron instituidas por el papa León III en Roma (Guilmard, 2009: II).

- Procesiones estacionales, con origen también en Roma, se desarrollaron probablemente de las fiestas aniversarios de los mártires (Baldovin, I987: I43I47).

Estas letaniae forman una base importante de los procesionales, siendo su lugar habitual de depósito, después del gradual. Sin embargo, aquí sólo será de nuestro interés el concepto de letanía como forma litúrgica-musical.

${ }_{17}$ Para el Domingo de Ramos (CAO I852 DF).

I8 Sobre su etimología, véase Baldovin (I987: 205-209). 
Ésta puede referirse a varios momentos diferentes, como por ejemplo a la Letanía de los Santos, Letanía Lauretana, Letanía como parte de la misa, etc. (Huglo \& Foley, "Litany”).

La letanía parece ser originaria de Antioquía, en tiempos de san Juan Crisóstomo, siendo una forma de oración para los feligreses más fácil que el silencio. Esta formula de diálogo entre Dios y su fieles tuvo (y tiene) mayor uso en los ritos de la liturgia oriental que en la occidental. De hecho, la iglesia occidental adaptó e imitó estas letanías de diversos modos, aunque las formas litánicas supervivientes de la liturgia franco-romana quedaron en dos: la capitella de psalmis y la letanía de los santos (Dalmais, Gy, Jounel, \& Martimort, 1987: 154-I55).

La letanía podría definirse como una fórmula de plegaria colectiva, sencilla y popular, dicha por lo general antes de la despedida de los catecúmenos, de cuya ejecución estaba encargado normalmente el diácono o uno de los lectores. Éstos, sin recitar una verdadera y propia fórmula eucológica, se limitaban a enumerar sucesivamente ante la asamblea una serie de demandas y deprecaciones, a cada una de las cuales el pueblo respondía con una palabra de súplica: Kyrie eleison; Miserere nobis; Te rogamos, audi nos; o semejantes (Righetti, 1955: 236).

Este género puede distinguirse de otras fórmulas responsoriales por la relativa brevedad de sus partes, a veces paralela a sus elementos constitutivos de llamadarespuesta, otorgando al sistema una percepción de insistencia de interpretación rítmica (Huglo \& Foley, "Litany")

\section{Letania de los santos y su aplicación procesional}

La letanía de los santos estimuló en cierto grado a aquellos cristianos que participaban en las procesiones de la liturgia en Roma (Dalmais et al., 1987: 155).

Según M. Righetti, las letanías suelen acompañar a las procesiones, así que no es extrańo encontrar este tipo de preces dentro de un procesional. En este sentido, el autor iguala las letanías a las procesiones penitenciales y lustrales, porque al final de las mismas se cantan estas fórmulas de súplica o intercesión (Righetti, 1955: 236).

Este tipo de letanías (de los santos) incluyen un listado de nombres de santos seguidos cada uno de la aclamación Ora(te) pro nobis, que precede a una serie de intercesiones de petición contra calamidades morales o físicas que son contesta-

19 La referencia también muestra, entre otros, una detallada descripción de las letanías según el tipo de liturgia. 
das con las súplicas Liberanos, Domine o Te rogamus, audi nos. La triple repetición del Kyrie al principio y al final de estas preces pasó a ser práctica habitual en el siglo IX, aunque se tiene constancia del canto de esta formula litánica (Kyrie eleison - Christe eleison - Kyrie eleison) como respuesta a las peticiones desde, al menos, el siglo Iv, según Hiley (Hiley, I993: 150). Cierran las letanías una conclusio que comprende, entre otros, un Agnus Dei, un Pater Noster y la oración que proceda (Coens, 1936: 5).

El culto de los santos debe su origen al culto de los difuntos, que se remonta a la prehistoria y se puede encontrar en diversas culturas y religiones. ${ }^{20}$ Para el rito cristiano, sus inicios parten del culto a los mártires (difuntos), pasando por el culto a los no mártires (ascetas y vírgenes), obispos, hasta su ulterior desarrollo con el culto a la translación de las reliquias (Dalmais et al., I987: I23-I33).

En otras palabras (Buzwell, 2006: 26):

"Según la creencia popular, la jerarquía del Cielo se ordenaba siguiendo líneas similares a las de la jerarquía sobre la Tierra: Dios como rey, Cristo como príncipe, María como reina y los santos actuando como cortesanos. Vistos como intercesores entre Dios y el género humano, los santos estaban ahí para salvar la distancia abismal entre Dios y el mundo. Durante la Edad Media, los santos representaban la faz humana y compasiva del Reino de los Cielos."

O en las de Coens (1936: 5):

"Nous voulons parler de la série, plus ou moins longue, d'invocations aux saints qui, à partir d'une certaine époque, se rencontre habituellement dans la prière de forme litanique, surtout dans las litanies dites majeures, après les supplications adressées au Christ, à la Vierge et aux Anges."

Si se tiene en cuenta esta jerarquía, no es extraño que, dentro de la iglesia, cierren la lista las santas féminas.

Al final de las letanías de los santos, se incluye un listado de deprecaciones y peticiones que da paso a la conclusión final, con sus respectivas oraciones y preces.

Por otro lado, debemos señalar que, en las deprecaciones y peticiones de estas letanías de los santos, hallamos un listado hagiográfico que ayuda en numerosas ocasiones a localizar la procedencia (y data crónica indirectamente en algunos casos) del manuscrito en el que se encuentran, pues además de la lista universal

${ }^{20}$ Sobre este aspecto, véase Brown (198I). 
de santos, este tipo de letanías suelen incluir ciertos nombre asociados a ciertas festividades locales.

C. Roederer nos muestra un párrafo claramente ejemplificador de lo citado en la introducción de su tesis doctoral (Roederer, 197I: I):

"Especially reflective of local practice was the choice of intermediaries addressed in the penitential litanies, a fact which often has helped scholars to determinate the provenance of a repertory."

Algunos especialistas (e.g. Coens, 1936: 9-IO) han explicado el gran desarrollo del listado de invocaciones de las letanías por el carácter especial de las ceremonias a las que va destinada, tales como las procesiones, a veces de larga duración en tiempo y espacio. Ilustrativo de este suceso es el caso de la celebración de la Bendición de las Fuentes Bautismales, cuyo rito es bastante extenso, además de tener la función de acompañar una procesión.

M. Gerbert, de Sankt-Blasien, lo expresa del siguiente modo (Gerbert, I776: IO):

"Haec litania propter plurima sanctorum nomina secundum exigentiam temporis sufficere possunt ad quamlibet processionem quantumvis longam."

Preces

El término preces igualmente puede designar diversos significados. Según el Diccionario de la Lengua Española, la palabra hace referencia a varios conceptos relacionados con el repertorio litúrgico: versículos de la Sagrada Escritura, oraciones de la Iglesia, ruegos y súplicas, y oraciones dirigidas a Dios, a la Virgen o a los santos. Por eso, no es de extrañar que a veces algunos autores utilicen este término para referirse a cualquier tipo de forma del repertorio litúrgico. Sin embargo, en el presente contexto, su delimitación es bastante clara.

Podemos definir preces, en los ritos occidentales, como una serie de peticiones breves en forma de versículos y respuestas. Aunque en las liturgias mozárabe-hispánica y galicana forman una categoría específica de canto, en el rito romano son confinadas al oficio de Prima para los Domingos feriados (Grove Music Online, "Preces").

Su origen proviene de la liturgia hispana y tuvo también su reflejo en otros ritos como el ambrosiano y el céltico (Anguita Jaén \& Fernández López, 2008: 158). 
Estas preces gozaron de un éxito vivo en su época, porque asociaban al pueblo de manera muy directa con la liturgia: el diácono recitaba un versículo que concretaba la intención de la oración y la muchedumbre repetía en seguida el estribillo de la supplicatio (Huglo, 1955: 36I).

Desde el punto de vista literario, estas oraciones litánicas presentan un gran interés, pues pertenecen al género de la poesía rítmica y cuentan entre los ejemplos más antiguos de este género.

Aunque están ligadas por su forma a otros cánticos litánicos, ${ }^{2 \mathrm{II}}$ las preces se pueden distinguir de las letanías por ser aquéllos isosilábicos, con estribillo pensado para el pueblo y, algunas veces, abecedarios (Anguita Jaén \& Fernández López, 2008: 17I).

\section{Las preces en los procesionales}

La vinculación de las preces con el repertorio procesional es clara. De hecho, éstas suelen aparecer escritas junto a antífonas procesionales (Hiley, 1993: 317).

Para el caso que nos ocupa, los procesionales aragoneses presentan las preces de origen aquitano que se cantan en las procesiones de las Letanías Menores o Rogativas, celebradas tres días antes de la Ascensión.

Como ha sido anticipado, éstas toman como modelo las preces hispánicas y remontan su origen a la época en la que los intercambios entre la liturgia hispana y la liturgia del sur de la Galia eran frecuentes. Más concretamente aparecen en los manuscritos aquitanos después de las antífonas de procesión para las Rogativas, con una función claramente procesional, aunque siempre en último lugar, justo antes de la Misa. Una rúbrica hace preciso el momento exacto de su ejecución. En los procesionales aragoneses aparecen estas preces pertenecientes al grupo de las liturgias "hispano-galicana" (Huglo, I955: 382), de modo similar al del repertorio procesional aquitano a lo largo de los siglos x a XIV (ClémentDumas, 200I: 780-789).

Estas son, con sus respectivos versículos, las siguientes:

- Miserere Pater juste et omnibus indulgentiam dona.

- Miserere Domine supplicantibus omnibus da nobis veniam.

- Rogamus te Rex seculorum Deus sancte jam miserere peccavimus tibi.

2I Sobre este aspecto, véase Brockett (2006). 


\section{Versus o himnos procesionales}

Existe en este caso un claro conflicto terminológico. El género musical que se describe a continuación ha sido denominado de dos formas diferentes a lo largo de la historia. Este hecho ha dado lugar a que diversos especialistas lo clasifiquen de diversos modos, aunque siempre en la misma línea argumental:

Por ejemplo, D. Hiley lo incluye dentro del apartado "Hymns", más concretamente como himnos procesionales (Hiley, 1993: 146):

"Hymns were often sung in processions. [...] A large proportion of processional hymns have a refrain. [...] There appear two series of twelve and five items respectively usually called versus (rather than hymnus)."

Aunque luego el autor le dedica unas líneas, incluyéndolo también como versus en el apartado de "Latin liturgical songs", aunque aquí significa composición latina posclásica de los siglos v, vi y viI, como por ejemplo, aunque más tardío, el versus Gloria laus et honor de Teodolfo, año 78I (Hiley, I993: 239).

En la misma línea encontramos la aportación de M. Huglo, quien define versus como himno con estribillo (Huglo, 2000: 120):

"[Le Gloria laus] présente un exemple caractéristique de ce genre que, des cette époque on dénomme le "versus», c'est-à-dire l'hymne à refrain : ici, la mélodie du refrain est différente de celle des strophes confiées à la schola."

R. Messenger los engloba también dentro de los himnos procesionales (Messenger, 1949: 379-380):

"Gautier, in his Histoire de la Poesie liturgique au Moyen Age: Les Tropes, has made the hymn just cited the starting point for his discussion of the versus, the name by which, in his opinion, the authentic medieval processional hymn came to be identified. [...] Gautier observes that the versus is always chanted, always accompanied by musical notation and is also distinguished by a refrain."

Y T. Bailey, lo indica del mismo modo (Bailey, I97I: I74-I75):

"There were three hymns sung in the processions of Sarum [...] The two other hymns were En rex venit and Gloria laus et honor, both for Palm Sunday."

Este modo de clasificar el versus como himno no es extraño dado que el término "himno" es quizás la palabra más vaga de toda la terminología litúrgico- 
musical (Szövérffy, 1989: 29 y ss.). San Agustín ya escribió páginas de discusión con respecto al significado del mismo ${ }^{22} \mathrm{y}$, además, como hemos visto, los himnos tuvieron, en principio, una clara función procesional (Hughes, 1995: 37).

\section{Descripción}

El versus es un término formal que es usado frecuentemente en música medieval, donde, al menos, puede significar tres conceptos diferentes. Para este trabajo, sólo son de interés dos de ellos y en este apartado sólo uno. ${ }^{23}$

La primera acepción se presenta en el apartado dedicado a los responsorios (vid. infra), como sección interna de los mismos. Aparece en los libros litúrgicos con la abreviatura $V$. o $V s$. y hace referencia al versículo que ha de cantar el solista como parte del responsorio. ${ }^{24}$

La segunda, describe el versus como una pieza poética musical formada por versos métricos, pero que se distinguen de los himnos no sólo porque carecen de doxología y no forman parte del oficio, sino también por la costumbre característica de ańadir a cada estrofa una serie de versos (revertere) a modo de ritornello o estribillo. Su texto no depende de otros textos preexistentes y su función es la de acompañar una acción antes o durante la misa, o bien como parte de los Tridium Paschale (Berendes, 1973: 20-25).

Los versus, probablemente como imitación de un uso litúrgico bizantino, comenzaron a florecer en las Galias hacia mediados del siglo Ix y fueron escritos para cantarse principalmente durante las procesiones (Righetti, 1955: 619). M. Berendes atribuye este hecho a la aparición de unas nuevas formas métricas, independientes de otras formas litúrgicas, introducidas en el proceso de galicanización del rito romano en la reforma carolingia (Berendes, I973: I-II).

La mayor parte de los expertos ubican la aparición del término versus, en su sentido técnico, en San Gall, en el siglo x, cuando el himno procesional fue mayormente desarrollado. La mayor colección de este tipo de himnos fueron recogidos en un códice de San Gall de c. 930 (CH-SGs 38I ${ }^{25}$ y otras fuentes

${ }_{22}$ Augustinus, Enarratio in Ps. Clxviii, PL 37, 1947 (new edition: Sancti Augustini Enarrationes in Psalmos CI-CL (CC XL, Pars X, 3), Turnhout, 1956, 2176-2177).

${ }_{23}$ Sobre aspectos detallados de su etimología y contextos, véase Crocker («Versus»).

${ }^{24}$ Téngase en cuenta que el versículo de la antífona no suele aparecer con esta abreviatura, sino como P. o Ps., para indicar el versículo del salmo (psalmus).

${ }_{25}$ Sankt Gallen, Stiftsbibliothek 38I (códice compuesto por versaria, himnos, tropos y secuencias, originario de St. Gall, c. 930). 
del cenobio suizo, como por ejemplo un procesional del mismo monasterio del siglo XII (CH-SGs 360). ${ }^{26}$

R. Messenger lo expresa, sin hacer distinción en la nomenclatura, del siguiente modo (Messenger, 1949: 380):

"Perhaps this word, capable of varied meanings, was found convenient o identify the new category of hymns and adopted by the hymn writers of St. Gall for that purpose. [...] These men were all writers of processional hymns or versus which found their way into the liturgical books of St. Gall.”

Según M. Huglo (2000: II9-I20), algunas de las composiciones métricas que debemos a los poetas de la época carolingia han sido escritas en los libros litúrgicos aportados por Roma, entonces cerrados a textos versificados, pues Roma y Lyon no adoptaron los himnos en la recitación del Oficio hasta el siglo XII. De este modo se pudieron incorporar con los usos galicanos, sobre todo en la liturgia de la Semana Santa. Éstos fueron principalmente los versus:

- El Gloria laus de Teodolfo de Orleans, para la procesión del Domingo de Ramos, con melodía del estribillo diferente de las estrofas.

- La letanía de Tinieblas Qui passurus, durante las tres últimas jornadas de Semana Santa, al final del oficio nocturno.

- El verso Tellus ac aethera jubilent, para el Mandatum (Jueves Santo). En la misma jornada, el canto para la unción del santo crisma: $O$ redemptor sume carmen.

- Para el Viernes Santo, en la función de la Adoración de la Cruz, el Pange lingua.

FORMAS DEL DENOMINADO FONDO PROCESIONAL PRESTADO

Se consideran piezas del fondo procesional prestado a aquellos cánticos tomados de otros libros litúrgicos de la Misa o del Oficio, que fueron incluidos dentro de los libros procesionales y que no forman parte del fondo procesional propio. Dada la diversidad encontrada en los procesionales europeos y el carácter de este estudio, sólo se tendrán en cuenta aquellos géneros que aparecen en el corpus escogido; los códices procesionales aragoneses.

${ }^{26}$ Sankt Gallen, Stiftsbibliothek, 360 (procesional de St. Gall, siglo XII). 


\section{Antifonas del oficio}

Dado que el término ha sido ya descrito, se dedicarán unas líneas para contextualizar la antífona tomada del repertorio del Oficio con función procesional. No obstante, existen abundantes trabajos sobre algunas antífonas procesionales de este tipo (e.g. Pressacco, 1995).

Muchas de las antífonas que eran cantadas en las procesiones de los Domingos y en las celebraciones del santoral (i.e. Sunday and Saint's processions) fueron tomadas prestadas del oficio nocturno del mismo día (Hiley, I993: I04).

Igualmente fueron tomadas, como sucede con el caso de los responsorios que veremos más adelante, del oficio de vísperas, sobre todo para la parte dedicada a los santos, cuyas antífonas fueron extraídas habitualmente de la antífona ad Magnificat de esa misma hora. Por esta razón, las antífonas procesionales "prestadas" de los oficios suelen ser antífonas sin versículo. En nuestro estudio, rara vez hemos hallado una antífona de este tipo con versículo y menos con salmo, hecho que coincide con lo que sucede en los análogos europeos.

He aquí un ejemplo de una antífona tomada prestada del Oficio:

- a./ Hodie illuxit nobis laetus (CAO 3102, para san Pedro), que hallamos en procesionales bajomedievales normalmente en la misma celebración.

\section{Responsorios del Oficio}

Este tipo de piezas musicales son tratadas como cantos responsoriales (estilo de ejecución) porque en ellos el coro responde con un refrán a versículos entonados por el cantor. Los responsorios, por su forma interpretativa, están íntimamente ligados a la salmodia responsorial, que es un tipo de canto dentro de las primeras manifestaciones musicales de la primitiva iglesia cristiana. De hecho, el uso del término podemos encontrarlo ya en el siglo Iv (Egeria, san Basilio, san Atanasio, san Ambrosio y san Agustín), quienes hacen referencia a la forma de cantar salmos de forma responsorial (Helsen, 2008: 9-10). No obstante, según el Grove Music Online, la primera descripción del término como género de canto litúrgico o forma propia independiente no aparece hasta el siglo vi en la Regla de san Benito (Cutter \& Maiani, «Responsory»).

Habitualmente, los responsorios son cantos adornados que aparecen intercalados entre las largas lecturas de la misa y del oficio, con las que tienen una estrecha relación (Marot, 1963; Martimort, 1992). 
Su triple función, estructural, estética y dramática, es la de contestar a la lectura, romper la monotonía de la lección y expresar los sentimientos que agradan a la asamblea durante la lectura respectivamente (Righetti, I955: I23I).

El responsorio consta de dos elementos: ${ }^{27}$ el corpus o responso, cantado por la schola, y el versículo, ${ }^{28}$ reservado al solista. Después de éste, la schola repite el corpus:

- o bien entero (uso romano), y se habla de repetición a capite, como en el gradual de la misa,

- o bien una parte, llamada reclamo (uso galicano), conocida como repetición a latere o presa, indicada en el manuscrito mediante la capitalización de la primera letra de la palabra donde comienza la repetición o mediante la abreviatura $P$.

Su interpretación, de forma general, queda fijada del siguiente modo: el solista o cantor entona el incipit, después la schola canta el resto del corpus del responsorio, para ser seguido del versículo, que será cantado por el solista. A continuación, los cantores responden o el corpus completo (uso romano) o el final del corpus (reclamo) desde la presa (uso galicano); para pasar después a entonar la doxología (por el canto de nuevo, si la hay) y, finalmente, volver a repetir el responsorio (completo o desde la presa).

Este sería el esquema: ${ }^{29}$

$$
\mathrm{R}-\mathrm{V}-\mathrm{P} / \mathrm{R}-\mathrm{D}-\mathrm{P} / \mathrm{R}
$$

Sin embargo, al igual que sucede con las antífonas, hecho que se justifica por el ahorro del soporte de escritura, la presentación de los responsorios en los libros exige el conocimiento de su estructura, ya que: I) se presenta el responsorio seguido de su versículo, y 2) las repeticiones a latera o presas vienen vagamente indicadas. El uso de la abreviatura $P$. para indicar la presa no es muy difundido. En los procesionales aragoneses, rara vez aparece dicha abreviatura. Más bien,

27 Sigo aquí a Huglo (I988: 25).

${ }^{28}$ La terminología en inglés tampoco hace una gran distinción en este término: versículo del responsorio y versículo del salmo (verse) frente al verso como forma poética propia (versus).

${ }_{29} \mathrm{R}$ = Corpus del responsorio completo, $\mathrm{V}=$ Versículo, $\mathrm{P}=$ Corpus del responsorio desde la presa, $\mathrm{D}=$ Doxología. Otro esquema en Asensio Palacios (2003: 284). 
suele señalarse el comienzo de la presa con la capitalización de la primera letra de dicho reclamo. En otros manuscritos, a veces podemos incluso no encontrar señal alguna de reclamo, con lo que tendremos que esperar al final del versículo para hallar una o dos sílabas que nos indiquen dónde hemos de volver para comenzar el reclamo pertinente. Además, a veces podemos encontrar que estas sílabas pueden dar lugar a equívoco, por existir varias posibilidades de retorno en el texto del responso, en cuyo caso habrá que recurrir a la música para establecer cuál es el punto de vuelta en dichas repeticiones.

\section{Responsorios con función procesional}

No sólo se ha manifestado la posibilidad de encontrar responsorios con función procesional, sino que existe una tipología de procesionales llamados "responsoriales" ${ }^{30}$ Algunos especialistas lo han expresado como sigue (Martimort, Dalmais, \& Jounel, 1983: 236):

"Ils [les répons] peuvent être exécutés comme chants processionnels."

En este caso, su utilización y destino difiere de la norma, ya que los responsorios que encontramos en los procesionales son formas musicales independientes. Es decir, son cantos propios que han de ser interpretados, al igual que las antífonas, en las procesiones, sin ningún otro tipo de vinculación salvo la que indique la rúbrica.

Hay que señalar que el responsorio como forma procesional ha sido poco estudiado. Estos responsorios, que vamos a denominar "procesionales", son tomados de otros libros litúrgicos; normalmente de los antifonarios y de los breviarios.

D. Hiley localiza su procedencia concretamente en el repertorio del oficio de vísperas o de los nocturnos de maitines de la misma celebración a la que va destinada la procesión (Hiley, I993: I04, 318). Sirva de ejemplo de este fenómeno el responsorio Vidi Dominum sedentem (CAO 7578), destinado habitualmente, en los procesionales, para la festividad de Todos los Santos y que encontramos en la mayor parte de las fuentes manuscritas ${ }^{31}$ como responsorio prolijo de las primeras vísperas para Omnium Sanctorum (santoral, I de Noviembre) o como

${ }^{30}$ Véase Huglo (1999, 2004: I, t. iv, 48*)

${ }^{31}$ Referencias y fuentes consultadas en CANTUS (Lacoste, Kolácek, \& Helsen, 20II-). 
primer responsorio, del primer nocturno de maitines en la festividad De Prophetis (temporale, aestate).

Los responsorios para uso procesional, fueron ańadidos en un cuarto estadio de formación de los libros procesionales. El motivo fue la adición de un repertorio diverso al de las letanías y rogativas, destinado a las procesiones de los Domingos y otras festividades, para ser celebradas entre la hora Tercia y la Misa solemne de estos días (Huglo, 1999, 2004: I, 37*).

Esta idea coincide, sin duda alguna, con el hecho de la adición de responsorios en el repertorio general de canto llano entre los siglos XI y XIV (Maiani, I998: 255):

"It is well known that there was an explosion of responsory composition in the eleventh through the fourteenth centuries, particularly in the north for the commemoration of newly canonized saints, feasts of only local interest, rhymed offices, and the like."

Colette, igualmente nos da una explicación similar, si bien algo matizada (Colette, 1976: 33):

"Les répons forment le répertoire habituel des processions dominicales et festives, au cours desquelles ils rappellent les offices du temporal et du sanctoral auxquels ils sont empruntés. Ils peuvent aussi remplacer les antiennes stationnales des Litanies majeure et mineures."

\section{Particularidades en antifonas y responsorios procesionales}

Aparecen en los procesionales medievales aragoneses y en los europeos (siglos XII$\mathrm{xv}$ ) una serie de rúbricas y piezas que pueden inducir a hacer dudar en la clasificación de las piezas como antífonas o responsorios (procesionales).

Se trata de los siguientes casos: $:^{32}$

- Antífona con versículo, que es convertida en responsorio mediante el simple cambio de rúbrica.
Ejemplo: ${ }^{33}$ a./ Christus resurgens
$>>$
r./ Christus resurgens
v./ Dicant nunc
$>>$
v./ Dicant nunc

${ }^{32}$ En los ejemplos se indica cómo aparecen en los códices (columna derecha) y cómo deberían aparecer según las fuentes primitivas (columna izquierda).

33 CAO 1796. 
- Antífona sin versículo, a la que le ha sido añadida una rúbrica indicando un versículo en un punto concreto dentro de la misma pieza. A su vez, es convertida en responsorio como en el anterior caso.

$$
\begin{gathered}
\text { Ejemplo: }:^{34} \text { a./ Christe Pater } \quad>\quad \text { r./ Christe Pater } \\
\text { v./ Sed tu }
\end{gathered}
$$

- Responsorio, aunque en su lugar se indique antífona con versículo:

$$
\begin{array}{ccc}
\text { Ejemplo: }^{35} \text { r./ Judea et Jerusalem } & > & \text { a./ Judea et Jerusalem } \\
\text { v./ Constantes } & \text { v./ Constantes }
\end{array}
$$

No es poco común, además de estos casos, encontrar ciertos cambios en las rúbricas por despiste o desconocimiento del copista:

- Antífona sin versículo, que es convertido en responsorio mediante el simple cambio de rúbrica.

Ejemplo: ${ }^{36}$ a./ Cum rex gloriae $\quad>\quad$ r./ Cum rex gloriae

\section{Himnos}

El término "himno" es, como hemos visto, un concepto vago y difícil de definir (Szövérffy, 1989: 29). No obstante, podemos considerarlo, dentro de la monodia latina, como sigue (Anderson et al., "Hymn"):

"The Latin hymn is a strophic composition, sung in the Divine Office, with a metrical poetic text and a predominantly syllabic melody. 'Hymn' here designates compositions for the Office, as distinguished from other liturgical poetry."

Como se observa, la definición restringe casi completamente este concepto únicamente al Oficio, excluyendo otros himnos de la misa o de las procesiones. Del mismo modo, apunta J. C. Asensio, cuando define los himnos latinos como (Asensio Palacios, 2003: 288):

$34 \mathrm{CAO}$ i784.

$35 \mathrm{CAO} 7040$.

${ }^{36}$ Antífona de origen galicano y uso aquitano, copiada en dos procesionales aragoneses. Sobre esta antífona en particular, véase Pressacco (1995), cit. supra. 
"[...] composiciones estróficas cantadas principalmente durante el oficio divino. Se dividen en dos grandes grupos, los himnos en prosa y en verso."

Desde luego, estas definiciones se ajustan a nuestro objetivo para este apartado: los himnos del Oficio que han sido tomados prestados con función procesional y que aparecen en los libros procesionales. Sin embargo, como en toda categorización o conceptualización de un término, existen diversas opininiones al respecto.

Por ejemplo, en la misma definición dada por el Grove Music Online, se dan ciertas ambiguedades que inducen a pensar en los versus o himnos procesionales definidos en apartados anteriores (Anderson et al., "Hymn"):

"In the Middle Ages some hymns were also sung outside the Divine Office, such as Pange lingua for the Veneration of the Cross on Good Friday, and stichic hymns for processions."

Como se ve, su definición es dificultosa. B. Turner no puede expresarlo mejor refiriéndose a la himnodia ibérica (Turner, 1995: 474):

"The subject of the liturgical Office hymn is huge."

Lo que parece claro es que su uso, desde la Antigüedad (antigua liturgia cristiana) hasta la Plena Edad Media, se multiplicó, especialmente durante los siglos X-XI, junto a otros elementos asociados a los mismos himnos. La creciente libertad de los compositores de este género se observa en el aumento de la utilización de literatura homilética y exegética en los mismos (Szövérffy, I989: 135). ${ }^{37}$ Un ejemplo de ésto lo constituye el repertorio de himnos compuestos (y tomados) del Oficio, que sirven para las procesiones ceremoniales en la celebración de mártires y sus reliquias (Messenger, 1950: 192).

Por su parte, los himnos del oficio del viejo rito hispánico no guardan mucha relación con los del rito franco-romano (Szövérffy, 197I; Thorsberg, 1962). Sin embargo, si comparamos el repertorio de himnos del oficio que aparecen en fuentes hispanas después de la reforma carolingia con el de otras regiones geográficas de Europa encontraremos resultados diferentes que resultan sugerentemente significativos (Bernadó, 1993; Gutiérrez González, 1989, 2004).

${ }^{37}$ Sobre el desarrollo de las formas hímnicas, véanse las pp. 32-56 de esa misma referencia. 


\section{Otras piezas del fondo procesional prestado}

Como hemos mencionado, otras formas litúrgico-musicales pueden aparecer en los libros procesionales. Es más, es común encontrar en la parte final de los libros procesionales piezas litúrgico-musicales de casi cualquier tipo, con función procesional o no. Por esta razón, listamos seguidamente, de forma alfabética y a título meramente informativo, aquellas formas litúrgico-musicales que aparecen en los procesionales aragoneses, sean procesionales o no. Evidentemente, indicamos sólo éstas por razones de espacio. Además, este mismo argumento y la falta de interés para este trabajo, nos obliga a no describir dichas formas, aunque sí las ejemplificaremos con una pieza en los casos posibles.

- Benedicciones episcopales: Princeps ecclesiae custos ovilis.

- Improperia: Popule meus qui feci tibi.

- Oraciones.

- Prosas: Natalitia cantantibus / Quia verbum hodie.

- Sanctus.

- Tractos: Sicut cervus desiderat.

- Tropos: Una sabbati surrexit valde mane.

\section{CONCLUSIONES}

Este estudio ha permitido conocer los principales tipos de formas litúrgico-musicales que fueron copiados para uso procesional en los libros de la liturgia latina a lo largo de la Edad Media.

A pesar del nivel de detalle aportado en este trabajo, el alcance del mismo ha limitado de alguna manera las posibles conclusiones.

Por un lado, se hace patente la dificultad de clasificación del repertorio procesional, pues puede formar parte de diversas ocasiones de la liturgia en Occidente, incluso como parte de la misa u oficio. No obstante, no pocos autores opinan que el repertorio procesional no forma parte del repertorio de la misa o del oficio sino que es un repertorio diferente e independiente de aquéllas. De hecho, la creación de libros específicos con este repertorio (procesional) corrobora esa idea. De cualquier modo, dado que el repertorio procesional fue fijado desde tiempos muy tempranos y posteriomente se fueron añadiendo otras piezas al mismo, existen dos claros y definidos tipos de piezas procesionales, que hemos denominado "fondos". 
El primero de ellos, aquí designado como fondo procesional propio, es el que viene escrito tanto en los primeros graduales como en los primeros procesionales autónomos, lo que indica la gran importancia de los ritos procesionales en la liturgia altomedieval. Además es el que incluye las piezas procesionales más antiguas. En ellos se incluyen antífonas largas y ornadas con exclusiva función procesional (Collegerunt, Immutemur habitu, etc.), preces antiguas de origen hispano-galicano, versus (o himnos procesionales) cuyo origen se remonta a los siglos v y vi, así como letanías y otros cánticos litánicos donde la participación de los fieles estaba asegurada.

El segundo fondo lo configura aquel repertorio prestado de otros libros litúrgicos y momentos de la liturgia; principalmente del Oficio, que era reutilizado para uso procesional. En este repertorio encontramos responsorios (tomados de los nocturnos principalmente), otras antífonas procedentes del oficio de vísperas del mismo día (ad magnificat), himnos de las horas, y otras piezas, musicales y no musicales, como oraciones, benedicciones, tropos, secuencias, etc., entre otros.

Finalmente, a modo de conclusión, debemos seńalar que, el libro procesional, o mejor dicho, las formas litúrgico-musicales procesionales, son conformadas, al igual que los repertorios de la Misa y del Oficio Divino, por un complejo sistema jerárquico basado en múltiples combinaciones de piezas litúrgico-musicales que se ordenan según un número de factores relacionados con la institución que los encargó componer.

\section{REFERENCIAS}

Anderson, W., Mathiesen, T., Susan, B., Ward, T. R., Caldwell, J., Temperley, N., \& Eskew, H., "Hymn" (rev. Septiembre 20I4), Grove Music Online. Oxford Music Online, http://www.oxfordmusiconline.com/subscriber/article/grove/ music/13648.

Andrés Fernández, D., 2012: El procesional y su música en Aragón en la Baja Edad Media / The processional and its music in Aragon in the Late Middle Ages, Tesis doctoral: Universidad de Zaragoza.

—, 2013: "In die Purificatione beata Maria virginis. Música y liturgia en el medievo aragonés", Anuario Musical, 68, pp. 3-I6.

Anguita Jaén, J. M., \& Fernández López, M. C., 2008: "Las preces hispánicas: puesta al día y novedades", Exemplaria Classica. Journal of Classical Philology, I2, pp. I55-I80. 
Asensio Palacios, J. C., 2003: El canto gregoriano: historia, liturgia, formas. Madrid: Alianza Musica.

Bailey, T. W., 1968: The ceremonies and chants of the processions of the Western Church: with special attention to the practice of the Cathedral Church of Salisbury, PhD thesis: University of Washington.

-, 1971: The processions of Sarum and the Western Church. Toronto: Pontifical Institute of Medieval Studies.

Baldovin, J. F., 1987: The urban character of Christian worship: the origins, development, and meaning of stational liturgy. Vol. 228. Orientalia Christiana Analecta. Roma: Pontificium Institutum Studiorum Orientalium.

Berendes, M. B., I973: The Versus and its use in the medieval Roman liturgy. $\mathrm{PhD}$ thesis: Unversity of Pittsburgh.

Bernadó, M., I993: "Sobre el origen y procedencia de la tradición himnódica hispánica a fines de la Edad Media", Revista de Musicología, I6 (4), pp. 23352353.

Brockett, C. W., 2006: Letania and preces: music for Lenten and Rogations litanies. Musicological Studies 85. Ottawa: Institute of Mediaeval Music.

Brown, P. R. L., 1981: The cult of the saints: its rise and function in Latin Christianity. London: SCM.

Buzwell, G., 2006: Los santos en los manuscritos medievales. Madrid: AyN.

Claire, J., 1980: Le répertoire grégorien de l'offce. Structure musicale et formes. Paper presented at the Le chant grégorien, patromoine artistique de l'Europe, Actes du Colloquie International de Musicologie en l'honneur du XIVe centenaire de S. Benoit.

Clément-Dumas, G., 200I: Le processionnal en Aquitaine : genèse d'un livre et constitution d'un répertoire ( $X^{e}-X I I I^{e}$ siècle). Thèse de doctorat: Université FrançoisRabelais de Tours.

Coens, M., 1936: "Anciennes litanies des saints". Analecta Bollandiana, 54, pp. 5-37.

Colette, M.-N., 1976: Le répertoire des Rogations d'après un Processionnal de Poitiers (XVI siècle). Paris: Centre National de la Recherche Scientifique.

Crocker, R. L., "Versus", Grove Music Online. Oxford Music Online (rev. septiembre 20I4), http://www.oxfordmusiconline.com/subscriber/article/grove/music/29247.

Cutter, P. F., \& Maiani, B. "Responsory: I. History of form”, Grove Music Online. Oxford Music Online (rev. septiembre 20I4), http://www.oxfordmusiconline. $\mathrm{com} /$ subscriber/article/grove/music/23247. 
Dalmais, I. H., Gy, P.-M., Jounel, P., \& Martimort, A. G., 1987: Principles of the Liturgy. The church at prayer: an introduction to the Liturgy, vol. I. Collegeville: Liturgical Press.

Gerbert, M., I776: Vetus liturgia alemannica. Sankt Blasien: Tip. San-Blasianis.

Guilmard, P., 2009: "La Litanie Majeure et les processions de la Messe: répertoire de chant à Rome et en Gaule la deuxième partie du viII ${ }^{\mathrm{e}}$ siècle", Rivista internazionale di musica sacra, 30 (I), pp. 7-6I.

Gutiérrez González, C. J., I989: "El Himnario de Huesca: nueva aproximación”, Anuario Musical, 44 (I), pp. 23-60.

—, 2004: "Procedimientos de creación y adaptación en los himnos litúrgicos medievales en España", Revista de musicología, 27 (2), pp. 815-840.

Gy, P.-M., 1990: La liturgie dans l'histoire. Paris: Saint-Paul / Du Cerf.

Helsen, K. E., 2008: The great responsories of the Divine Office: aspects of structure and transmission. $\mathrm{PhD}$ thesis: Universität Regensburg. Retrieved from http:// www.opus-bayern.de/uni-regensburg/volltexte/2008/IO3I/

Hesbert, R.-J., 1935: Antiphonale Missarum Sextuplex. Bruxelles: Vromant \& Co.

—, 1963-1979: Corpus Antiphonalium Officii, Rerum Ecclesiasticarum Documenta. Roma: Herder.

Hiley, D., I993: Western plaintchant: a handbook. Oxford: Oxford University Press.

Hughes, A., I995: Medieval manuscripts for mass and office: a guide to their organization and terminology. Toronto: University of Toronto Press.

Huglo, M., "Processional". Grove Music Online. Oxford Music Online (rev. septiembre 20I4), http://www.oxfordmusiconline.com/subscriber/article/grove/ music/22384.

—, I955: "Les preces hispaniques des graduels aquitains empruntées à la liturgie hispanique", Hispania Sacra, 7, pp. 36I-383.

—, 1988: Les livres de chant liturgique. Turnhout: Brepols.

—, 1999, 2004: Les manuscrits du processionnal. RISM B-XIV. München: Henle Verlag.

—, 2000: "Les versus de Venance Fortunat pour la procession du Samedi-saint à Notre-Dame de Paris", Revue de Musicologie, 86 (I), pp. II9-I26.

Huglo, M., \& Foley, E., "Litany: 4. Monophonic litanies in the Roman liturgy". Grove Music Online. Oxford Music Online (rev. septiembre 20I4), http://www. oxfordmusiconline.com/subscriber/article/grove/music/16769.

Huglo, M., \& Halmo, J., "Antiphon”. Grove Music Online. Oxford Music Online (rev. septiembre 20I4), http://www.oxfordmusiconline.com/subscriber/article/grove/music/oio23 
Lacoste, D., Kolácek, J., \& Helsen, K. E., 20II: CANTUS: A database for Latin Ecclesiastical Chant. Retrieved from http://cantusdatabase.org/

Maiani, B., I998: "Reading and responsories: the eight-century Night Office lectionary and the Responsoria prolixa", Journal of Musicology, I6 (2), pp. 252282.

Marot, H., 1963: "La place des lectures bibliques et patristiques dans l'office latin". Lex orandi, 35, pp. I5I-I54.

Martimort, A. G., I955: "Les diverses formes de procession dans la liturgie", La Maison-Dieu, 43, pp. 43-73.

-, I992: Les lectures liturgiques et leurs livres. Turnhout: Brepols.

Martimort, A. G., Dalmais, I. H., \& Jounel, P., 1983: La Liturgie et le temps. L'Eglise en prière : Introduction à la liturgie, vol. IV. Paris - Tournai: Desclée.

Messenger, R. E., I949: "Medieval processional hymns before IIoo", Transaction and proceedings of American Philological Association, 80, pp. 375-392.

—, I950: "Processional hymnody in the later Middle Ages", Transaction and proceedings of American Philological Association, 81, pp. 185-199.

Nowacki, E., 1990: The performance of office antiphons in twelfth-century Rome. Paper presented at the Cantus Planus papers read at the 3 rd meeting (Tihany, Hungary, September 1988).

Palazzo, E., 1998: A history of liturgical books: from the beginning to the thirteenth century. Collegeville: The Liturgical Press.

"Preces", Grove Music Online. Oxford Music Online (rev. septiembre 20I4), http:// www.oxfordmusiconline.com/subscriber/article/grove/music/22278.

Pressacco, G., 1995: L'antifona "Cum rex gloriae Christus» del Processionale Aquileiese. Paper presented at the Cantus Planus papers read at the 6th meeting (Eger, Hungary, 1993).

Righetti, M., 1955: Historia de la liturgia. Madrid: Biblioteca de Autores Cristianos.

Roederer, C. D., I97I: Eleventh-century Aquitanian chant: studies relating to a local repertory of processional antiphons. $\mathrm{PhD}$ thesis: Yale University.

Saulnier, D., 2005: Des variantes musicales dans la tradition manuscrite des antiennes du repertoire romano-franc. Thèse de doctorat: Ecole Pratique des Hautes Etudes (Sciences historiques et philologiques), Paris.

—, 20IOa: "Des variantes musicales dans la tradition manuscrite des antiennes du répertoire romano-franc", Études Grégoriennes, 37, pp. 5-I5.

—, 20Iob: "Les antiennes dans la tradition Romano - Franque", Études Grégoriennes, 37 , pp. $17-59$. 
Szövérffy, J., I971: Iberian hymnody: survey and problems. Wetteren: Classical Folia.

-, 1989: Latin hymns. Turnhout: Brepols.

Thorsberg, B., 1962: Etudes sur l'hymnologie mozarabe. Stockholm: Almquist \& Wiksell, imp.

Turner, B., 1995: "Spanish liturgical hymns: a matter of time", Early Music, 23 (3), pp. 472-482. 